Article

\title{
Constructing the Public in Roadmapping the Transition to a Bioeconomy: A Case Study from the Netherlands
}

\author{
Durwin H.J. Lynch ${ }^{1, *}$, Pim Klaassen ${ }^{1}{ }^{\mathbb{C}}$, Lan van Wassenaer ${ }^{2}$ and Jacqueline E.W. Broerse ${ }^{1}$ \\ 1 Athena Institute for Research on Innovation and Communication in Health and Life Sciences, Faculty of \\ Science, Vrije Universiteit Amsterdam, 1081 HV Amsterdam, The Netherlands; p.klaassen@vu.nl (P.K.); \\ j.e.w.broerse@vu.nl (J.E.W.B.) \\ 2 Wageningen Economic Research, Droevendaalsesteeg 4, 6708 PB Wageningen, The Netherlands; \\ Lan.vanWassenaer@wur.nl \\ * Correspondence: d.lynch@vu.nl
}

Received: 16 March 2020; Accepted: 10 April 2020; Published: 15 April 2020

\begin{abstract}
In recent years there has been increasing attention to the transition toward a bioeconomy. From comparable transitions toward sustainability, we know that transitions require integral, inclusive approaches toward developing a long-term strategy, focusing not only on technological innovation, but also on involving the public. This is not easy. Public engagement encompasses diverse forms of public and civil society participation, and it is crucial to understand the specificities of these interactions and their effects on potential transition pathways. We present a conceptual-analytical paper where the focus lies on understanding sense-making practices in the construction of publics in the bioeconomy. Using a case-study approach, this article describes five partialities of the constructed public in the bioeconomy and analyzes the orchestration, productive dimensions and effects of these constructions. Our analysis offers a new perspective on, and appreciation of, the partiality of different forms of public participation, and varying degrees in which possibilities of system change in the bioeconomy transition are inclusive or exclusive toward differentially constructed publics. This offers an alternative, constructive way of exploring actor dynamics and politics in system change. We aim to contribute to a more nuanced and integral interpretation of public engagement in sustainability transitions, which is relevant to actors from academia, policy, industry and other spheres relevant to the bioeconomy transition.
\end{abstract}

Keywords: public engagement; bioeconomy; transition management; STS; participative collective; public construction; sustainability transition; participatory mechanism; coproduction; the Netherlands

\section{Introduction}

Over the last two decades, there has been increasing interest in the bioeconomy. Making the transition to a bioeconomy is perceived as being able to address various challenges, including those concerning energy security and worsening environmental conditions-the most prominent of which is climate change induced by greenhouse gases (GHG) [1-3]. Acknowledging that there are many definitions for the bioeconomy [4], in this paper we build on McCormick and Kautto [5], who define the bioeconomy as 'an economy where the basic building blocks for materials, chemicals, and energy are derived from renewable biological resources'. The bioeconomy is generally portrayed as a positive, stimulating economic development with significant potential, for instance for agriculture, the production of food and beverages, pharmaceuticals, agro-industrial products and energy production [6]. Nonetheless, there are concerns about possible negative social and environmental side effects. For instance, scaling up the bioeconomy potentially comes with controversial practices, such as promoting monocultures and 
land grabbing $[7,8]$. Its polarizing potential warrants an exploration of the - possibly critical—public perceptions of the bioeconomy.

Although there has been an increase in literature on the transition to a bioeconomy, this revolves mainly around technological, chemical and biological issues entailed in the transition [9-11]. Less attention has been paid to its social, ethical and economic aspects, and the voice of the public regarding such matters. For a transition to a bioeconomy to take place, however, the bioeconomy should not only be technically and economically [12] viable, but also socially desirable and ethically acceptable $[1,7,9]$. Indeed, it has been argued that a successful transition to a bioeconomy requires system-wide changes involving society, academia, governments and industry [13]. If political and innovation developments (continue to) ignore ongoing social debates, this could hamper the transition [4]. Transitions not only entail systemic changes in modes of production and consumption, but are also accompanied by changes in beliefs, values and governance [14]. It has been argued that there is a need for broader social dialogues on the bioeconomy, as well as more attention paid to social studies focusing on its non-technological aspects, giving voice to a broader array of social stakeholders, including citizens $[7,9,15]$. Such broader dialogues can take different forms and formats-for instance, stakeholders and citizens can be brought together directly or indirectly [16,17]. What these different forms and formats of participation actually signify for the bioeconomy transition, however, remains unclear.

A few studies have attempted to close this knowledge gap [17-21]. Mustahalati [18] explored the need to include citizens in a responsive forest-based bioeconomy and discussed the fact that responsive governance involves several key aspects of change, such as citizens' values, interests, know-how and environmental entitlements. This requires an interactive collaborative approach that enables citizens and institutions to meet and debate the development of living environments. One important challenge is to develop strategies that prevent powerful actors from dominating the discussion, hampering ordinary citizens from expressing their values in, and opinions on, this transition. Stern et al. investigated the social perspectives on the bioeconomy in Austria [17]. They argued that the current discourse has mainly been driven from a strategic top-down level, which leads to the failure to include social actors, and consequently to the acceptance of reduced engagement. Their study sheds light on sustainable consumption - a topic the participants in the study considered important, and which is of particular interest for creating an inclusive bioeconomy by focusing on consumers' active involvement.

Since public engagement encompasses diverse forms of civil society participation, it becomes crucial to understand the specificities of different forms of interaction and their impacts on potential transition pathways. All forms of participation are by definition exclusive, partial, framed in particular ways and subject to overflows. Having a solid understanding of their details provides opportunities to optimize public engagement in the bioeconomy transition, in such a way that, in addition to attempting to be inclusive, it is also responsive to public input. In this article, to contribute to this effort, we build on constructivist work in Science and Technology Studies (STS) and pay close attention to the construction, performance, productive dimensions and effects of what we will refer to as "collectives of participation" [22,23].

This study aims to explore the construction of various publics in the bioeconomy by drawing on a specific case, the "Societal Roadmap for the Bioeconomy in the Netherlands" project. We reflect on two public engagement elements of this project: (1) seven Focus Group Discussions (FGDs) in which 57 citizens participated, and (2) three multi-stakeholder workshops in which 29 representatives from academia, industry, government and civil society participated. First, we analyze how the publics were orchestrated, by looking at the enrollment processes and how these participatory collectives were mediated. Here we ask which actors and (related) knowledge remain excluded and what competing visions emerge. Second, we seek to understand the productive dimensions and effects of these participatory collectives. Here we ask how issues are defined, different visions valued, and how they are integrated in the transition pathway. Moreover, we analyze what identities the constructed publics come to embody. 


\section{Toward an Understanding of the Construction of Publics}

There are several established theoretical branches pertinent to sustainability transitions, for example the Multi-level Perspective, Strategic Niche Management, Transition Management and Technological Innovation systems. What these theories have in common is that they focus on explaining how technical configurations become stabilized and how transitions can be steered. They also share a relatively technocratic and expert-oriented nature, thereby potentially obscuring possible influences on the dynamics of transitions by the public (e.g., ordinary citizens, Civil Society Organizations (CSOs), consumers). Various scholars call for more inclusive sustainability transition processes, highlighting particularly the relative lack of attention to the general public [24-26]. Smith [27] argued that public engagement encompasses diverse forms of public and social participation, and calls for more detailed work on these different forms, seeking to understand their interactions and effects on potential transition pathways.

Public engagement is often approached through political science and theories of democracy, emphasizing its normative surplus as a way of legitimizing the outcomes of research or policy-making. A constructivist perspective on public engagement, rooted in STS, takes a slightly different angle. Whereas the former tends to focus more on elements of procedural justice and normative principles that define predetermined models of what constitutes good deliberation and participation, constructivist approaches view all forms of participation as emergent co-productionist phenomena and as social experiments in themselves. Approaching public engagement from an STS perspective, then, entails paying close attention to the construction, performance, productive dimensions and effects of particular instances of practicing public engagement [28-30]. An assumption in this constructivist perspective is that all forms of participation are simultaneously shaped by, and actively shape, human subjectivities, objects of concern and models of participation.

This paper presents such a constructivist approach to public engagement. Our focus is on a case-study conducted to facilitate the development of a societal roadmap to the bioeconomy, a central element of which was to give a voice to the public in general, as well as to specific stakeholders. The analytical framework used is inspired by the work of Chilvers and Longhurst [22,31], who have studied the construction of the public in the energy transition.

All collectives of participation start with the inclusion or exclusion of actors via mechanisms of enrollment. Consequently, the constitution of these actors highlights the productive ways in which approaches to mediation construct objects (or issues), subjects (or publics/participants) and models of participation (or procedural formats/configurations). Chilvers and Longhurst present a framework (Figure 1) in which the mutual interaction between these three dimensions is presented as constitutive of their own emergent and co-produced features. Furthermore, they highlight that the settings in which situated participatory collectives emerge are shaped by (and in turn shape) existing orders (systemic, institutional and constitutional states relating to the three dimensions). Concretely, this boils down to interpreting how "public" actors become involved, how the design of the participatory mechanisms used comes about and what their effects are. As such, we study how actors come to be included or excluded, what mechanisms of enrollment are in place and what this means for the public identity assumed. 


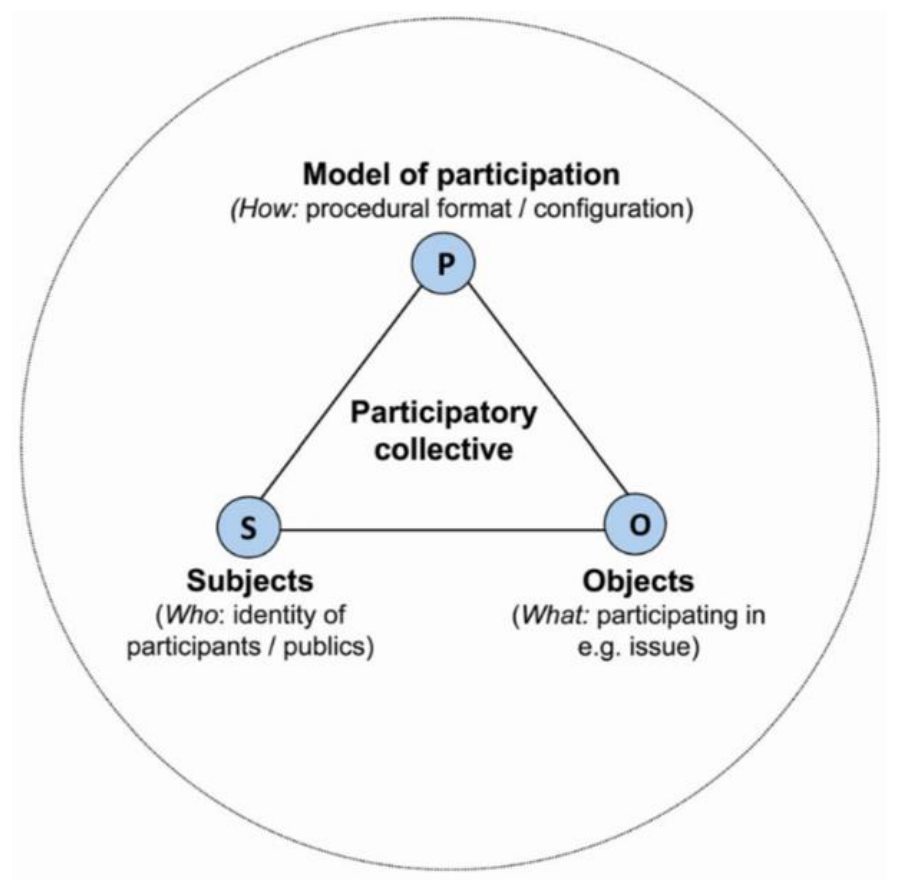

Figure 1. Socio-material participatory collectives emerge in the co-productive relationships existing between models of participation, subjects and objects, and in relation with their specific context. Adapted from Chilvers and Longhurst (2016), p. 590.

According to Chilvers and Longhurst [22], understanding participation as emergent and co-produced offers a number of analytical possibilities, including gaining insight into the orchestration and the productive dimensions and effects of emergent participatory collectives. First, the orchestration of a collective of participation focuses on processes of enrollment and mediation. Here, enrollment refers to the way different actors are drawn into a particular form of participatory collective practice and definition of the issue at stake. Mechanisms of enrollment can be highly centralized and controlled by a small number of actors in the collective. This is especially true for formalized "technologies of participation" such as citizen panels, focus groups or other established deliberative participatory techniques which have standardized designs. Enrollment can also be more distributed and fluid, as viewed in informal and citizen-led forms of engagement. Mediation refers to the way in which a participatory collective is held together by different devices, processes, skills or technologies of participation. All forms of participation by definition lead to exclusions, are always partial, framed in particular ways and subject to overflows.

Second, the productive dimensions and effects of emergent participatory collectives. This means a focus on the ways in which diverse collectives of participation construct particular definitions of (1) models of participation), (2) the public and (3) the issue at stake. First, the relations between actors and participants in a participatory collective create a particular model of participation, which can range from consensual to antagonistic. Emergent collectives produce publics through constructing particular identities of the actors involved, such as "naïve" citizens or "pure" publics (assumed to have limited prior knowledge or simply being representative of a wider public), or "interested" or "affected" citizens (with a personal attachment to the object of participation; or more active or innovative citizens, who are expected to bring about forms of distributed action). Finally, issues can be subject to powerful framing effects, especially in institutionally orchestrated processes.

The theoretical notions described above highlight that "the public" is not static, nor can it be easily captured, since it does not exist in a pregiven natural state. Rather, it is actively constructed, orchestrated, mediated and interpreted. 


\section{Methods and Materials}

\subsection{Case Selection and Description}

In order to empirically explore the constructions of the public in the bioeconomy we draw on a case called "Societal Roadmap for the Bioeconomy in the Netherlands". This case is chosen because of its unique and innovative methodological approach, involving the public in governance toward the bioeconomy transition in the Netherlands. The case is therefore helpful for understanding more about the participatory mechanisms, the productive elements and the complexities that arise when taking an inclusive and holistic approach to long-term strategy development.

The project was a formal and discrete state-sponsored exercise of participation on the issue of bioeconomy in the Netherlands, and was conducted in 2014-2015. It involved a range of actors from academia, industry, government, non-governmental organizations (NGOs) and the general public, who came together to identify non-technological opportunities, threats and other considerations relevant for the governance of the transition toward a bioeconomy. The project focused on three distinctive technological applications in the bioeconomy: (1) biomaterials, (2) biorefineries and (3) biojetfuels. Two paths ran in parallel in the project. The first path focused on citizens' perceptions of the bioeconomy, while the second focused on the views of several stakeholder groups on governance issues entailed in the transition toward it.

The purpose of the first path was to identify Dutch citizens' perceptions of the bioeconomy. For this, a qualitative research approach was used, with FGDs as the primary research method. In FGDs, participants respond to, and build on, the views expressed by other participants, stimulating shared creative thinking and providing an opportunity to gain in-depth insight into the participants' ideas, values, wishes and concerns [32]. This is particularly relevant for complex topics that require a process of familiarization and opinion forming. Three concrete bio-based technologies-bioplastics, small-scale biorefineries and biojetfuels-were selected as topics for in-depth exploration in the FGDs. The choice to focus on specific bioeconomic applications was made because discussions on something as abstract and poorly delineated as "the bioeconomy" was seen as risking only vague and superficial deliberations. Participants were selected from the general public, based on a diversity with respects to citizens' relationships with the technologies (direct consumers, residents and indirect consumers). In total, 57 Dutch citizens participated in seven FGDs, three of which dealt with bioplastics, two concerned (small-scale) biorefineries and two focused on biojetfuels. For a more elaborate overview of the participant selection, the structure of the FGDs and the analysis, see [16].

The purpose of the second path was to explore perceptions and evaluations of policy scenarios. To this end, three multi-stakeholder workshops with 29 participants from academia, NGOs, industry and government were held, on the topics of biomaterials, biorefineries and biojetfuels. Using the participatory Multi-Criteria Analysis (pMCA) method, the workshops explored how different scenarios are valued according to a large set of criteria that are weighted differently by different stakeholders (e.g., NGOs may assign more weight to $\mathrm{CO}_{2}$ reduction than to economic growth than the private sector). The participatory element entails the inclusion of different stakeholders in the workshops. The pMCA workshops followed the FGDs on the same technology routes. The researchers in the project aimed to incorporate the outcomes of the FGDs with citizens in the pMCA workshops.

\subsection{Case-Study}

In exploring this case, we are interested in two specific analytical themes developed by Chilvers and Longhurst (2016) and presented in Section 2 above. Thus, we first analyzed how the public was orchestrated, by looking at the enrollment processes and how the participatory collective was mediated. This entailed answering the questions about which actors and forms of knowledge were excluded, and what emerging competing visions could be identified. And second, we sought to understand the productive dimensions and effects of these participatory collectives. To this end, we posed several more 
questions: What was the model of participation? What identities do the constructed publics come to embody? How are issues defined and different visions valued and integrated in the transition pathway?

To answer these questions, we drew on a variety of materials: the FGD designs, transcripts of the audio recorded FGDs, the analysis of the FGDs (which has been published [16]), pMCA workshop designs, the outcomes of the workshops, informal participant evaluations at the end of the workshops and the project's final synthesis report [33]. Furthermore, email communication between the project team members and recruitment agencies were used to extract relevant justifications of the choices made. Personal reflective notes which were made after the FGDs and workshops, and during and after project meetings through participant observations, were also analyzed. An additional qualitative analysis of documentary grey and academic literature sources was used to deepen the analysis of the FGDs and pMCA workshops. These materials were coded against the two main analytical themes just outlined: the orchestration and the productive dimensions and effects of the participatory collective.

\section{Results}

In this section we discuss the construction of the public for the three different bioeconomy technologies-biomaterials, biorefineries and biojetfuels—and the two different objects, i.e., the general public's perception of each of these technologies and the stakeholders' views on appropriate governance models for the transition toward a bioeconomy in which these technologies are featured. In this project, the public was involved in two ways. First, citizens, as members of the public, were invited to discuss "public perceptions" of three bioeconomy technologies in designated FGDs-so citizens with citizens. Second, NGOs, as entities representing "the public", were invited to discuss strategic governance related to three bioeconomy technologies in designated pMCAs-so NGOs with other stakeholders. We focus primarily on the construction of the public in the bioeconomy, i.e., the citizens involved in the FGDs and the NGOs in the pMCA workshops. Specific results related to the other stakeholders' (academia, industry and government) perceptions of the issues are not incorporated in our analysis of how the issue was constructed by the public in this participatory collective.

\subsection{The Orchestration of the Public}

\subsubsection{Enrollment and Mediation}

Enrollment refers to the way different actors are drawn into a particular form of participatory collective practice and definition of the issue at stake. For the FGDs, enrollment was centrally organized via a recruitment agency, which was requested to follow a standardized design for selecting a "representative" sample of Dutch citizens. Two different recruitment agencies were involved, each with its own recruitment strategy. The first agency, which recruited for the FGDs on bioplastics, used its Facebook page to invite participants. It also used the snowballing technique, as recruited participants were invited to further recruit other participants. However, as a result, one of the FGDs comprised three acquaintances among the total number of six participants, heavily weighing on the FGD's internal dynamic; these three participants dominated the discussion and occasionally shared insider jokes. The second agency, which recruited for the FGDs on biorefineries and biojetfuels, actively matched participants from its own member database. This was, however, challenging for the FGDs on bio-refineries, as there was the additional criterion that participants had to come from the "De Achterhoek" (a rural region in the province of Gelderland) and live within $5 \mathrm{~km}$ distance of a farm. For all FGDs, participants received a standard reimbursement of $€ 30-40$. The only information the participants received upfront was that the FGD would be related to the topic of sustainability, and in order to participate they should have an interest in this. No further information on the bioeconomy or any of the three technological applications was given. This was done to avoid the possibility of participants informing themselves beforehand. A brief introduction to the technology was provided in a PowerPoint presentation during the FGD. 
The enrollment of the public in the pMCA workshops was also institutionally centralized, as this was controlled by key stakeholders of the project team. The aim was to have representatives of four stakeholder groups in each workshop: NGOs, academia, industry and government. Most of these stakeholders were already engaged in the bioeconomy, as most had previously signed a bioeconomy Manifesto (Retrieved from: https://www.biobasedeconomy.nl/wp-content/uploads/2011/10/ManifestBBE-def-29-sep.pdf, see also Section 4.2.3, Box 1, for an excerpt). In addition, several other people from a specific selection of organizations were invited to attend the workshop. The selected participants knew beforehand that they were invited because they represented a particular stakeholder group and had expertise in bioeconomy. Although NGOs can be considered to be representative of the public (including citizens), they were not invited with the explicit (pregiven) task to do so. The project was led by an NGO, which attended all three workshops, although each time represented by a different individual. The aim was to have representatives from two NGOs in each of the three workshops (the project leader and one other). For the pMCA on biojetfuels, however, the additional NGO dropped out at the last minute, leaving only the project leader to represent the NGOs.

Mediation refers to the way in which a participatory collective is held together by different devices, processes, skills or technologies of participation. In order to capture and provide exposure to the citizens' distinctive voice in the bioeconomy, and to prevent them from being potentially overshadowed by more dominant expert discussions, the deliberations with citizens were organized separately from those with stakeholders. The decision to keep these two groups-experts and non-experts-separate simultaneously meant designing and implementing different modes of participation. Furthermore, as the concept of bioeconomy is broad and encompasses a variety of technologies, applications and dimensions, each FGD and pMCA workshop dealt with one of the three bioeconomy technologies. Both the deliberations with citizens and those with stakeholders were mediated by professional facilitators from two research institutes that formed part of the project team: the FGDs by the Vrije Universiteit Amsterdam, and the pMCA workshops by Wageningen University. The research team from each university was independently responsible for the organization, implementation and analysis of their deliberations. Regular finetuning and reflection between the two teams took place to align the two paths.

\subsubsection{Exclusion and Resistance}

Since all forms of participation by definition lead to exclusion, are always partial, framed in particular ways and subject to overflows, we reflect in this section on which actors-and consequently on what knowledge-were consciously or inadvertently excluded, or resisted taking part in the participatory collective.

It could be argued that for the FGDs there was, to a certain extent, exclusion in terms of achieving a geographically representative sample of the population. This is mostly related to the practical and organizational decision-making aspects that arise when working in research projects that have a fixed timeline and budget to carry out the activities. For example, the FGDs on bioplastics and biojetfuels were held at the Vrije Universiteit, in Amsterdam, at a fixed time in the evening, during the week, which made it less convenient for potential citizens from other regions in the Netherlands to participate. The FGDs on biorefineries in De Achterhoek were held at a central location in the city of Doetinchem, but at a place that was less accessible for anyone using public transport. So, in order to be part of "the public", participants had to be (1) in the crossline of the recruitment agencies, (2) be willing to travel to the location at a specified date and time, and (3) in the case of biorefineries, also live close to a farm in the region of De Achterhoek. The exclusion does not, however, render the outcomes of the FGDs less valid, irrelevant or non-representative. It simply highlights that organizing FGDs comes with delineations, and this automatically causes exclusion of the general public.

In order to make the FGDs more "accessible" to all Dutch citizens, the project could have worked with campaigns and self-enrollment possibilities. However, the project organizers deliberately wanted to avoid attracting citizens who were already familiar with the topic, either because of their work or 
hobby, and whose views were therefore not representative of those of "the general public". Needless to say, the aim of FGDs was to elucidate diversity (breadth) and in-depth exploration of opinions, and not to achieve generalizable outcomes.

Similarly to the FGDs, the pMCA workshops excluded certain actors in their model of participation. First, it could be argued that the involved NGOs dealt primarily with environmental topics (Stichting Natuur \& Milieu, Milieu Centraal, IUCN NL), thereby excluding other NGOs or CSOs dealing with, for example, more health-related topics or consumer interests. Both practical and substantial reasons explain this. A practical reason is that a pMCA workshop can be conducted only with a limited number of participants, otherwise it will become harder to facilitate, so the organizers have to select, and therefore exclude. In order to achieve a wide variety of stakeholders' perspectives, this was limited to around 10-12 participants divided over four stakeholder groups. The majority of the selected stakeholders, including the NGOs, had signed the Manifesto. To a certain extent, these parties were "on the same page" on a variety of aspects related to the bioeconomy. However, within the bioeconomy there are also polarizing groups (see, e.g., [7]), and it seems that these different perspectives were excluded from the participatory collective in this project.

On a different note, and as will become evident from the model of participation (see Section 4.2.1), the pMCA workshops dealt with transition governance, and the commissioner of the project (Ministry of Economic affairs) attended all three workshops. The design of the workshops was focused on input from participants well acquainted with the bioeconomy and policy-making. It could therefore be argued that the general public was excluded from the pMCA process. At the same time, ensuring proper facilitation remains key, which requires keeping the workshop manageable in terms of the number of participants and safe in terms of potential power-plays. However, this set-up did jeopardize the inclusion of public perceptions of the bioeconomy as explored in the FGDs.

\subsection{The Productive Dimensions and Effects of Emerging Participatory Collectives}

\subsubsection{Model of Participation}

For the deliberations with citizens, the FGD method was used as a model of participation, and the FGDs were facilitated by researchers from the Vrije Universiteit Amsterdam. As the invited participants were not expected to prepare anything beforehand, the facilitators carefully designed and structured a script for the FGDs, in consultation with the project team (one NGO and two universities). For each of the three selected technological bioeconomy applications, a slightly different approach was taken, but, in general, each FGD consisted of five activities (see Table 1) and lasted for two hours.

In line with FGD guidelines, each FGD had on average eight participants, providing enough room to discuss in depth a variety of opinions related to the topic. Since the FGDs aimed at elucidating citizens' perceptions of the bioeconomy technologies, each design contained elements in which information on the technology was provided to the participants. The first activity provided more information on the technology via a PowerPoint presentation with neutral and factual information on how it relates to larger social challenges and what the technology entails. In the case of bioplastics, there were actual bioproducts that the participants could hold in their hands. This step is necessary, as it triggers participants to become acquainted with the technology by asking questions, giving reactions and thereby developing their opinion. Other activities discussed concrete examples of the technology. First, participants were requested to individually reflect on arguments in favor of, and against, the technology; second, they were asked to discuss this with each other. This enabled other participants to understand different perspectives and perhaps adjust their own perceptions. Collectively, participants were then asked to formulate important considerations for a successful development and implementation of the technology. Although the FGDs did not aim for participants to reach consensus, the final activity aimed at determining which considerations the participants collectively prioritized in each particular FGD. 
Table 1. General structure of the FGDs.

\begin{tabular}{l} 
Activity \\
\hline \\
Getting acquainted with the bio-based technology: \\
In order to assess the starting level of knowledge, the participants were individually \\
asked if they were familiar with the bio-based technology in question and what their \\
first thoughts or associations were. Subsequently, a short PowerPoint presentation \\
containing basic factual information on the subject was provided to the participants in \\
order to acquaint them with the subject. \\
Inventory of arguments for and against the bio-based technology: \\
The participants were individually asked to write down arguments for and against the \\
bio-based technology, after which each was asked to clarify their arguments. We \\
stimulated their thinking process by telling them that they could also write \\
"opportunities" and "concerns" related to the bio-based technology. The arguments \\
were all collected and clustered on a flip chart, according to the wishes of the \\
participants. \\
Individual prioritization of arguments: \\
For this exercise, each participant received three prioritization stickers. They were \\
asked to express their acceptance of the bio-based technology by individually \\
prioritizing arguments. Afterwards, a facilitated discussion took place to find out why \\
people prioritize certain arguments rather than others. \\
Formulate considerations for the bio-based technology: \\
During this step, participants were asked to identify criteria for a successful \\
implementation of bio-based technologies. The facilitator wrote down these \\
considerations on a flip chart. \\
Closure: \\
At the end of the FGD, the participants were asked to reflect on the discussions and \\
how they had experienced the FGD.
\end{tabular}

A central aspect of each pMCA workshop, facilitated by researchers from Wageningen University, was to discuss three policy scenarios in relation to the bioeconomy technological applications. The first was a demand-pull scenario in which the government supports bioeconomy developments by introducing incentives, such as green public procurement and subsidies that would increase demand. For the second scenario, technology-push, the government would stimulate technological bioeconomy developments by providing financial support for research and development (R\&D) and pilot and demonstration projects. In the third scenario, market-driven, the government would intervene less and allow the market to take initiatives with innovation strategies. All pMCA workshops followed a general structure (see Table 2) and lasted for three hours. Although the workshops contained elements of individually assigning weights and scores to indicators, these were used as a means to explore possibilities and discuss governance strategies in a collective way. Therefore, the model of participation can best be described as consensual.

The pMCA workshops were one-off events with no additional participatory configurations before or after the workshop. While most stakeholders' organizations were present only once, two organizations attended all the workshops. These were the commissioning party (Ministry of Economic affairs) and the NGO acting as project leader (Stichting Natuur \& Milieu). As a stakeholder group, Wageningen University and another government stakeholder (Rijksdienst voor Ondernemend Nederland, EN: Netherlands Enterprise Agency) were present in two of the three workshops. Therefore, only the latter two were able to contribute to the workshops by taking insights from the previous ones into account. Despite this possibility, there were varying representatives of these organizations at the workshops.

After each workshop there was a short informal evaluation with the participants and the project team, which served to improve the following workshop. For example, the first workshop (on biomaterials) was considered too abstract, and more concrete examples and delineation of the scenarios was considered desirable. The preliminary list of criteria was also considered too complex, and simplification was proposed. These aspects were considered for the design of the workshops on 
biorefineries and biojetfuels, so the methodology was refined over time. This shows that the topic of the bioeconomy is rather abstract and vague, not only for citizens. Even expert stakeholders, who are already engaged and involved in this topic, require concrete examples in order to properly discuss governance strategies.

Table 2. General structure of the pMCA workshops.

\begin{tabular}{|c|c|}
\hline Activity & Description \\
\hline \multirow[b]{2}{*}{1} & Discuss the policy scenarios \\
\hline & $\begin{array}{l}\text { Determine if the three scenarios were relevant and appropriate, and whether some } \\
\text { scenarios had to be adapted, removed or new scenarios should be added. }\end{array}$ \\
\hline 2 & $\begin{array}{l}\text { Discuss criteria and indicators } \\
\text { Determine whether the predefined criteria and indicators were appropriate, ensure that } \\
\text { everybody had the same understanding of these, and if necessary discuss } \\
\text { modifications, additions and removals. }\end{array}$ \\
\hline 3 & $\begin{array}{l}\text { Assign weights to criteria } \\
\text { All participants individually assigned weights between } 1 \text { and } 5 \text { to the criteria. } \\
\text { Assign scores to indicators }\end{array}$ \\
\hline 4 & $\begin{array}{l}\text { All participants assigned scores (between } 1 \text { and } 5 \text { ) to the expected effects of the } \\
\text { different scenarios on the criteria. Lower scores corresponded to negative effects, } \\
\text { higher scores to positive effects. }\end{array}$ \\
\hline \multirow{2}{*}{5} & Discuss scores \\
\hline & Plenary discussion of considerations of the different scenarios. \\
\hline \multirow{2}{*}{6} & Discuss scenario preferences \\
\hline & Discuss the implementation of the most preferred scenario. \\
\hline
\end{tabular}

\subsubsection{Defining the Public: Many Partialities}

This section will reflect on how the public was constructed through particular identities of the stakeholders and citizens involved in the participatory collective. Here we incorporate the work of Michael [34] and Braun and Schultz [35] on constructions of the public.

First, the FGD participants were invited to take part as "citizen members" of the Dutch public. This corresponds to what Michael calls the Public-in-General: " . . an undifferentiated whole that is distinguished from science that is itself characterized globally in terms of some key dimension." At the beginning of each FGD it was made clear to the participants that they were invited as the Public-in-General. However, each FGD also contained a particular activity in which the participants were asked to interpret aspects of the bioeconomy from a more specific identity. This is in line with what Michael defined as Publics-in-Particular: ". . . those publics that have an identifiable stake in particular scientific or technological issues or controversies." As Public-in-Particular, three roles were distinguished. The FGD on bioplastics asked participants to discuss their willingness to buy two concrete bioplastics, so playing the role of direct consumers, while the FGDs on biorefineries asked participants to perceive this technology from the perspective of residents. The FGDs on biojetfuels asked participants to discuss these from the perspective of indirect consumers. It was unclear which identity the participants embodied, or reacted from, when, for the final activity, they were asked to propose and prioritize general considerations for the development and implementation of the biotechnology.

The results of the FGDs [16] showed that participants easily switched between the identities, perhaps as a result of the guided process. What can be observed here is that as particular public identities are assigned to, and embodied by, citizen participants, they experience a more personal connection with the given technology. This enables them to reflect on different personal values that matter most, and to frame their perception accordingly. This perception is then shared with other participants, enabling knowledge integration. While in all FGDs the participants started on a positive note toward the bioeconomy technology, issues of personal costs and benefits became more important as they took up the particular, secondary identities. This will be further elaborated in Section 4.2.3. 
It was a deliberate choice to exclude citizens from taking part in the pMCA workshops. However, in line with Braun and Schultz [35], in the conceptualization of publics in governance arrangements, NGOs can be considered as the "Partisan Public": " . . organisations (not individuals) who hold strong collective opinions on the issue [at stake] or have a particular interest. They are also referred to as stakeholders or lobbyists." Therefore, we argue that the NGOs in the pMCA workshops represented not only their particular interest, discussing transition governance on an equal footing with other "expert" stakeholders, but also a different partiality of the public. On the other hand, citizens were framed as relevant actors for a successful bioeconomy transition. This can be seen through the defined criteria and indicators which were used to discuss the different policy scenarios. Table 3 presents the ranking of these criteria in each of the workshops. For the workshop on biomaterials, it shows that the "citizens' acceptance" was seen as an important, highly valued indicator, and related to the "willingness to buy". In the other workshops, "citizens' acceptance" and "health and wellbeing" were considered relevant, but of less importance.

Table 3. Rankings of the criteria indicators defined in the three pMCAs.

\begin{tabular}{cccc}
\hline Rank & Biomaterials & Biorefinery & Biojetfuels \\
\hline 1 & Carbon footprint & Carbon footprint & Carbon footprint \\
2 & Citizens' acceptance & Profit & Supply chain availability \\
3 & Biodiversity & Environmental impact & Job opportunities \\
4 & Production costs & Level playing field & Energy efficiency \\
5 & Consumer willingness to buy & Biodiversity & Profit \\
6 & Quality of products & Job opportunities & Competitive position NL \\
7 & Profit & Policy consistency & Level playing field \\
8 & Policy consistency & Citizens' acceptance & Citizens' acceptance \\
9 & Job opportunities & Health and wellbeing & Public investments \\
10 & Level playing field & Quality & Biodiversity \\
11 & Market share & Administration costs & Administration costs \\
12 & Administration costs & & \\
\hline
\end{tabular}

The input of citizens (as the Public-in-General) was limited to formulating criteria for a successful bioeconomy transition. Although NGOs can be considered as Partisan Public, only a few NGOs (with a strong focus on environmental issues) were involved. Other, more or less organized sectors of the public were not seen as stakeholders with the same "privileges", invited to discuss transition governance. For the first workshop (biomaterials), the highlights of the outcomes of the corresponding FGDs were presented orally to the stakeholders by the facilitator of the FGDs. The rationale of this was to provide a more nuanced view of public concerns, wishes and conditions for the stakeholders to consider when discussing the policy scenarios. However, since there were no citizens present to "own" to these outcomes, and all stakeholders were mainly focused on their own interests, the perceptions of citizens, and therefore also other partialities of the public, remained excluded from the discussions during the pMCA workshops. It was, however, mentioned to the participants that the final reporting to the commissioner would attempt to integrate insights from the FGDs with the outcomes of the pMCA workshops. This will be further reflected upon in Section 4.3.

\subsubsection{Defining Issues of the Bioeconomy}

Issues can be subject to powerful framing effects, especially in institutionally orchestrated processes. Although the concept of "bioeconomy" was not discussed as such with the FGD participants, they were able to substantiate their perceptions of the three concrete technologies that were introduced. The majority of the participants expressed positive associations with these technologies, linking these to notions such as sustainability, environmental friendliness, naturalness and green feeling. However, there were also negative associations, such as genetic modification, higher prices and improper land use. These framings were the result of a guided process of knowledge articulation undergone by the citizens. 
Overall, there seemed to be acceptance of the three applications of the bioeconomy technologies and the sustainability purpose they served (i.e., replacing fossil-based products). Citizens enjoyed being engaged in the discussions on this transition, as they find topics related to sustainability relevant. They were, however, more critical regarding how these applications would be framed and presented to the public. This became more evident when participants were asked to perceive the technology from a particular public perspective. For example, in the concrete case of a bio-based bottle for a specific drink, participants felt they were still buying "the drink" and not a sustainable bottle. As can be seen in the quote below, they became less willing to "pay more" as consumers, as this was seen more as greenwashing.

[the manufacturer] actually wants me to buy the beverage, they don't want me to buy the bottle. I won't buy the drink just because it is in a bioplastic.

(Bioplastics, FG1, P3)

In the case of a biobag, which could be used for shopping, participants were more interested in its quality, price and how it was made. Here the application of the technology was regarded as more positive. This is illustrated with the quote below.

It suggests a green and good intention of the producer, and such endeavors should be supported.

(Bioplastics, FG3, P6)

It is important to mention here that, contrary to the participants of the pMCA workshops, the FGD participants did not have a chance to study the topic beforehand. The FGD participants were therefore dependent on the information provided to them in the FGD to form an opinion. It is likely that the content of this information, as well as the way it was communicated, had some framing effect. While the FGD setting provided an opportunity to study this process of opinion forming in a more or less controlled environment, opinions can also be formed independently, without the mediating context of an FGD. Citizens are increasingly empowered and self-sufficient, and find ways to inform themselves through the internet and informal discussions, and form their opinions at their own pace.

The pMCA workshops did not devote particular attention to the framing of the bioeconomy by the different stakeholders. Therefore, not much can be said about how it was framed through the participatory collective. However, by enrolling stakeholders who previously signed the Manifesto, it can be assumed that these stakeholders were, to a certain degree, "on the same page". In Box 1 the main points of this Manifesto are presented, to give insight into the position to which they were signatory.

Box 1. Excerpt from the Dutch Biobased Economy Manifesto.

In conclusion, we, the signatories of this Manifesto:

- Commit ourselves in the pursuit of a sustainable bio-based economy that supports ecosystems and acknowledges people's basic necessities as preconditions;

- Commit ourselves to enter into partnerships to make the bio-bases economy come to practice in line with the stated principles;

- Agree as much as possible within legal frameworks, to inform each other about lessons learned, dilemmas and aspirations in order to build on the frameworks of a bio-based economy that offers opportunities for people, the environment and sustainable economic growth;

- Ask the Dutch government to:

- $\quad$ actively promote and communicate the stated principles nationally and internationally and to support in policy and associated financial instruments,

promote monitoring of the bio-based economy progress, including labour market and sustainability related information.

be take an open approach, and contribute to initiatives arising from our partnerships 


\subsection{Knowledge Integration: A Persistent Challenge}

\subsubsection{A Revised Configuration of the Participatory Collective}

In this section we briefly reflect on the model of Chilvers and Longhurst [22] and describe the co-productive relationships between the model of participation $(\mathrm{P})$, subjects $(\mathrm{S})$ and objects $(\mathrm{O})$ in the participatory collective. The case studied in this article shows a unique additional dimension to this model: a multiplicity of collectives of participation. Since the public was involved in two related-yet separate_-paths, the participatory collective became more enriched, yet complex and problematic. Below (Figure 2) we present this dual configuration, in which it becomes evident that not all relationships can be considered relational and co-productive. For the two models of participation, in this case FGDs (P1) and pMCA workshops (P2), the relation has been co-productive: there was regular finetuning and contemplation between the researchers designing these models of participation. The subjects, however, experienced less co-production: both the FGD participants (S1) and the pMCA workshop participants (S2) were kept separate from each other, and this implied less opportunities for learning and co-creation between the "non-expert" citizens and the "expert" stakeholders. Consequently, the objects were also less relational: discussing the desirability of three bioeconomy technologies (O1) versus discussing criteria and indicators for transition governance (O2).

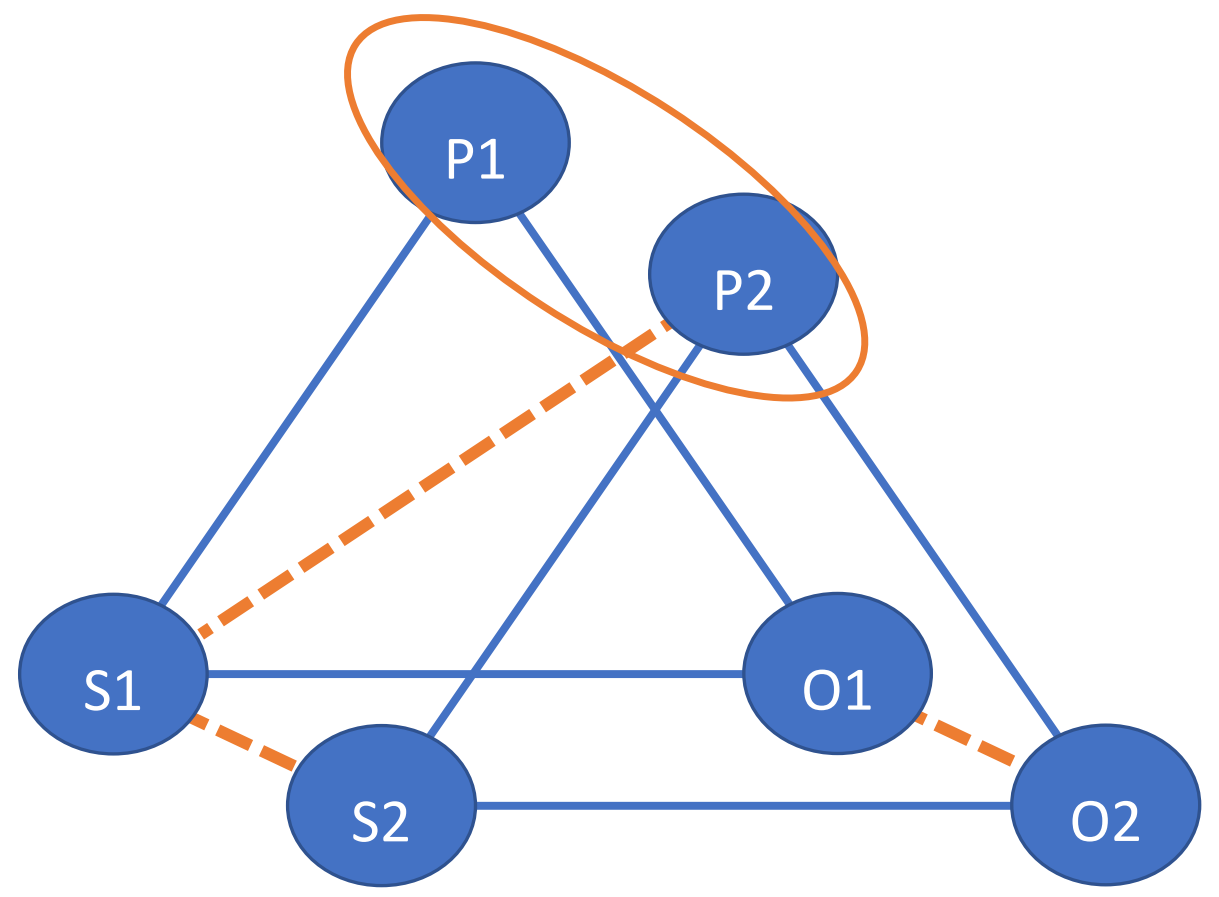

Figure 2. A configuration of dual models of participation.

In the project's final synthesis report these two paths were presented in two separate chapters, one focusing on the FGD outcomes and the other on the pMCA workshop outcomes. As becomes evident, certain partialities of the constructed public remained excluded from the actual decision-making arena, in this particular case taking an active part in the governance discussion of the transition toward a bioeconomy. While the Partisan Public (as one of the Publics-in-Particular) was considered appropriate to discuss governance strategies with other "expert" stakeholders, this was not the case for citizens (as the Public-in-General). As a result, although the project was inclusive with regard to the public, it cannot be said that the resulting roadmap on the bioeconomy is supported by the public. For the government, the license to operate remains therefore only partially supported, which means that the the roadmap may be less responsive to the public. 


\subsubsection{Striving for a Meaningful Deliberation}

In the case studied, the involved researchers regularly reflected on the process and results of the previous steps to realize a meaningful deliberation. This happened in different ways. First, the outcomes of the FGDs with citizens served as input for the design of the pMCA workshops. It was also attempted by including preliminary results of the FGD on bioplastics in the deliberations during the pMCA workshop on biomaterials. However, the stakeholders participating in the workshop were more interested in framing and portraying their own, and other experts' perceptions than in trying to understand and integrate the perspectives of citizens. They were directly integrating their co-constructions on the object through a particular model of participation-a model that lies closer to actual decision-making, thus having an increased chance of having a direct impact. The citizens' framing (as members of the Public-in-General) was reduced to "citizens' acceptance" and "consumers' willingness to buy", indicating a traditional way of positioning lay citizens exclusively as end-users, instead of co-creators of the transition process.

\section{Discussion}

\subsection{Main Findings}

In this paper, we explored the orchestration, the production dimensions and the effects of involving the public in the transition to a bioeconomy. One of our main conclusions from the FGDs is that, overall, citizens can be very supportive of the bioeconomy-relating it to visions of sustainability, reduction of GHG emissions, alternatives to depleting fossil-fuels-and yet still have varying degrees of resistance to certain applications of bioeconomy technologies, particularly by the industry. Furthermore, the public, as a broad and non-homogenous group, entertains widely diverging thoughts on a wide palette of aspects of the bioeconomy. There is no singular all-encompassing "public perception of the bioeconomy". In addition, in the project, the researchers perceived and valued the public differently. The public was implicitly and explicitly enrolled in one of five identity roles [34]:

- members of the general public, who possess commonsense knowledge and can discuss their appreciation of bioeconomy technologies in relation to social challenges;

- direct consumers of two different bioplastic applications, whereby citizens discussed desirability in relation to the willingness to buy;

- indirect consumers of biojetfuels, whereby the willingness to pay more for biotickets was explored;

- the affected public, possessing experiential knowledge by living near a farm where a small-scale bio-refinery could potentially be installed; and

- the partisan public, such as an organized group (NGO), expected to represent social concerns and wishes in expert-based discussions on transition governance.

These show five partialities of the constructed public, resulting from two models of participation. These models of participation, with their corresponding definitions of the issues at stake, are constantly being co-produced through the construction of collectives of participation. Moreover, regardless of how the public embodied these identity roles in the FGDs, experts in the pMCA workshops constructed "the public" in their own way-mostly as receptive end-users (or consumers) of the bioeconomy, whose acceptance of the bioeconomy needs to be monitored. This construction appears to emerge as a by-product both of the self-definition of these stakeholders as experts on one or another element pertinent to the transition toward a bioeconomy, which also brings along a delineated group of non-experts that is "the public", as well as the design of the arena in which they make sense of the public in relation to the governance of a transition toward a bioeconomy.

Our analysis highlights a tension between the inclusion and exclusion of participants. While the case studied in this article aimed to be inclusive, the overall participatory collective that was formed was partially framed and subject to "overflows" [36]. This means that certain actors and definitions of the issues were excluded. For example, excluded actors included stakeholders with an opposing 
standpoint to those who signed the Manifesto and citizens who were not in the crossline of the recruitment agencies or interested in sustainability issues. In some cases, these exclusions were deliberate and purposive, in others they were the unintended consequence of the orchestration.

Unlike experts from academia, industry or policy, or partisan public bodies, such as NGOs, citizens are not already and continuously engaged in the transition toward a bioeconomy. When thinking of engaging citizens as members of the Public-in-General, the focus is placed specifically on those citizens who are not educated on the topic, but who possess commonsense and experiential knowledge, as well as a value scheme in relation to socio-political and technological developments that is not specifically colored by their investment in the bioeconomy. It is such a heterogeneous and unstable group whose ways of giving meaning to the bioeconomy one would generally want to explore. These citizens need to go through a process of knowledge articulation, which entails familiarization for deliberate opinion forming. As a consequence, and because of time and resource constraints, their articulated, unique and distinctive knowledge became siloed, and their embodied identities were excluded from the process of knowledge integration with others-experts, stakeholders, policymakers-when criteria and preferences for transition governance were discussed. This is an important decision-making aspect of defining the societal transition pathway, where involved stakeholders participate and interact in order to develop support for policies (i.e., license to operate) and to engage actors in reframing problems and solutions through social learning [37]. We argue that this could ultimately hamper the overall effectiveness of integral, holistic transition governance, as policy-makers are now tasked with integrating the separately collected knowledge themselves, while lacking a clear license to operate granted by the "general public".

This case-study has shown how easily certain partialities of the public that have a substantial stake in the transition, but have less power, remain "ignored" or are framed according to specific interpretations. This highlights the need for a better, more substantial, involvement of the heterogeneous public, as also stressed by a number of other studies [7,9,10,38]. Chilvers and Longhurst [22] have called for a better analysis of the relationship between the way in which collectives of participation are configured and political openings/closings that occur with respect to models, publics and objects of participation. Our study responds to this call, showing how the configuration of FGDs and pMCA workshops in the bioeconomy can lead to political closing for a number of partialities of the constructed public.

\subsection{Strengths, Limitations and Future Perspectives}

The findings of our study are contextualized by many factors that are specific to the political and innovation culture of the Netherlands [39]. The governance approach to bioeconomy in this country focuses on co-creating a long-term vision that informs short-term action, on facilitating bottom-up, regional clusters and on promoting radical innovation through stimulating the cooperation between players with vested interests and frontrunners [37]. Since we are dealing with a transition that needs to happen in contexts that vary widely with regards to political and innovation cultures, as well as biocapacity [40], it becomes pertinent to investigate how such differences in culture weigh into what can or should be expected from how participative collectives are constituted [30]. Whereas in some contexts, such as the Netherlands, it is considered straightforward that public engagement is a prerequisite for a successful bioeconomy transition [37], in others it might not—or with different enactments [23]. The transition to a bioeconomy requires actions on a global scale, yet regional efforts are needed to demonstrate progress and to identify useful indicators that monitor the performance of a sustainable bioeconomy [41,42]. It is a challenge that takes on many forms to ensure that public participation does not turn into a meaningless or stripped-down strategic practice, in which official authorities pretend to listen to citizens while continuing the pursuit of their own vested interests and exerting their own power [23]. Contextualized case studies, such as the one presented in this article, can serve to shed light both on good practices as well as on blind spots or open-ended challenges-such 
as for instance knowledge integration. It is in this capacity that such studies can contribute to a more sustainable and inclusive transition to a bioeconomy [43].

Our analysis offers a new perspective on, and appreciation of, the partiality of different forms of public participation, and varying degrees by which possibilities of system change in the transition to a bioeconomy are inclusive or exclusive with regard to these publics. We are simultaneously being reminded of the complexities, or even the impossibility, of putting into practice anything even vaguely like a situation of ideal dialogue, of the importance, in our efforts to engage with them, to attend to the public with an ethics of care, and, as researchers, doing what we can to emancipate the voice of those who are affected but are not in the driver's seat. This offers a promising way of exploring actor dynamics and politics in system change. With this, we aim to contribute to a more sensitive, sensible and integral interpretation of public engagement in sustainability transitions-one that is relevant to actors from academia, policy, industry and other spheres relevant to the bioeconomy transition.

Our work adds to the growing body of literature focused on explaining transition actor dynamics, such as Farla et al. [44], where there is a particular interest in a greater understanding of designing and implementing innovative participation collectives and spaces of intervention in system change in transitions. Actors in transitions need to be reflexively aware of the partialities of the public and the impact that potential exclusions can have. Stakeholders have diverging views and priorities with regard to the policy objectives and interventions. Citizens are often interested in technological change [45] and progress toward more sustainable societies, but enrolling them in participatory collectives does require an appropriate participatory approach to make sense of current developments and to form an opinion on the developments and desirable futures $[23,31,46]$. Understanding this can help us design more effective or targeted policy interventions (be it with incentives such as subsidies, public procurement or behavioral "nudging" to induce changes).

\section{Conclusions}

Our case-study shows that there is no single all-encompassing "public perception of the bioeconomy". The constructed "public" has various partialities, thus highlighting the need for a better acknowledgement and involvement of diverse segments of the public in sustainability transitions. This requires appropriate experimentation with participatory research-an approach that takes time, provides room for contemplation, creativity and reflexivity, and that stimulates curiosity and appreciation toward the distinctiveness of non-expert knowledge and how this could substantially contribute to the transition pathways. By focusing on the latter, we will be able to develop technologies and policies that are not only inclusive, but also accepted by society. Although our case study was limited to the transition to a bioeconomy in the Netherlands, the findings are also likely to be applicable to other policy themes and, to some extent, to other countries.

Author Contributions: Conceptualization, P.K., J.E.W.B. and D.H.J.L.; Methodology, D.H.J.L., L.v.W. and J.E.W.B.; Analysis D.H.J.L. and P.K.; Data Curation, D.H.J.L.; Writing-Original Draft Preparation, D.H.J.L.; Writing-Review \& Editing, D.H.J.L., P.K., L.v.W. and J.E.W.B.; Visualization, P.K.; Supervision, J.E.W.B.; Project Administration, J.E.W.B.; Funding Acquisition, J.E.W.B. All authors have read and agreed to the published version of the manuscript.

Funding: This research was supported by BE-BASIC, an international public-private partnership (PPP) that develops industrial bio-based solutions to build a sustainable society (http://www.be-basic.org). This project was carried out under the Flagship "Embedding Biobased Economy in Society" of the BE-Basic program, funded by the Dutch Government's FES program.

Acknowledgments: The authors would like to thank Deborah Eade for English editing. In addition, the authors wish to thank the editor and the two anonymous reviewers for their constructive comments and suggestions for improving this manuscript.

Conflicts of Interest: The authors declare no conflicts of interest. The funders had no role in the design of the study; in the collection, analyses or interpretation of data; in the writing of the manuscript or in the decision to publish the results. 


\section{References}

1. Langeveld, J.W.A.; Dixon, J.; Jaworski, J.F. Development Perspectives Of The Biobased Economy: A Review. Crop Sci. 2010, 50 (Suppl. 1), 142. [CrossRef]

2. Priefer, C.; Jörissen, J.; Frör, O. Pathways to shape the bioeconomy. Resources 2017, 6, 10. [CrossRef]

3. Pfau, S.F.; Hagens, J.E.; Dankbaar, B.; Smits, A.J.M. Visions of sustainability in bioeconomy research. Sustainability 2014, 6, 1222-1249. [CrossRef]

4. Meyer, R. Bioeconomy strategies: Contexts, visions, guiding implementation principles and resulting debates. Sustainability 2017, 9, 1031. [CrossRef]

5. Mccormick, K.; Kautto, N. The Bioeconomy in Europe: An Overview. Sustainability 2013, 6, $2589-2608$. [CrossRef]

6. Scarlat, N.; Dallemand, J.F.; Monforti-Ferrario, F.; Nita, V. The role of biomass and bioenergy in a future bioeconomy: Policies and facts. Environ. Dev. 2015, 15, 3-34. [CrossRef]

7. Mukhtarov, F.; Gerlak, A. Away from fossil-fuels and toward a bioeconomy: Knowledge versatility for public policy ? Environ. Plan. C Politics Space 2017, 35, 1010-1028. [CrossRef]

8. Butler, C.; Demski, C.; Parkhill, K.; Pidgeon, N.; Spence, A. Public values for energy futures: Framing, indeterminacy and policy making. Energy Policy 2015, 87, 665-672. [CrossRef]

9. Bugge, M.M.; Hansen, T.; Klitkou, A. What is the bioeconomy? A review of the literature. Sustainability 2016, 8, 691. [CrossRef]

10. Aquilani, B.; Silvestri, C.; Ioppolo, G.; Ruggieri, A. The challenging transition to bio-economies: Towards a new framework integrating corporate sustainability and value co-creation. J. Clean. Prod. 2018, 172, 4001-4009. [CrossRef]

11. Haider, T.P.; Völker, C.; Kramm, J.; Landfester, K.; Wurm, F.R. Plastics of the Future? The Impact of Biodegradable Polymers on the Environment and on Society. Angew. Chem. Int. Ed. 2019, 58, 50-62. [CrossRef] [PubMed]

12. Reim, W.; Parida, V.; Sjödin, D.R. Circular business models for the bio-economy: A review and new directions for future research. Sustainability 2019, 11, 2558. [CrossRef]

13. De Besi, M.; McCormick, K. Towards a bioeconomy in Europe: National, regional and industrial strategies. Sustainability 2015, 7, 10461-10478. [CrossRef]

14. Kern, F.; Smith, A. Restructuring energy systems for sustainability? Energy transition policy in the Netherlands. Energy Policy 2008, 36, 4093-4103. [CrossRef]

15. Wesseler, J.; Von Braun, J. Measuring the Bioeconomy: Economics and Policies. Annu. Rev. Resour. Econ. 2017, 9, 275-298. [CrossRef]

16. Lynch, D.H.J.; Klaassen, P.; Broerse, J.E.W. Unraveling Dutch citizens' perceptions on the bio-based economy: The case of bioplastics, bio-jetfuels and small-scale bio-refineries. Ind. Crops Prod. 2017, 106, 130-137. [CrossRef]

17. Stern, T.; Ploll, U.; Spies, R.; Schwarzbauer, P.; Hesser, F.; Ranacher, L. Understanding perceptions of the bioeconomy in Austria-An explorative case study. Sustainability 2018, 10, 4142. [CrossRef]

18. Mustalahti, I. The responsive bioeconomy: The need for inclusion of citizens and environmental capability in the forest based bioeconomy. J. Clean. Prod. 2018, 172, 3781-3790. [CrossRef]

19. Sanz-Hernández, A.; Sanagustín-Fons, M.V.; López-Rodríguez, M.E. A transition to an innovative and inclusive bioeconomy in Aragon, Spain. Environ. Innov. Soc. Trans. 2019, 33, 301-316. [CrossRef]

20. Sanz-Hernández, A.; Esteban, E.; Garrido, P. Transition to a bioeconomy: Perspectives from social sciences. J. Clean. Prod. 2019, 224, 107-119. [CrossRef]

21. Hempel, C.; Will, S.; Zander, K. Societal perspectives on a bio-economy in Germany: An explorative study using Q methodology. Int. J. Food Syst. Dyn. 2019, 10, 21-37.

22. Chilvers, J.; Longhurst, N. Participation in transition(s): Reconceiving public engagements in energy transitions as co-produced, emergent and diverse. J. Environ. Policy Plan. 2016, 18, 585-607. [CrossRef]

23. Carvalho, A.; Pinto-Coelho, Z.; Seixas, E. Listening to the Public-Enacting Power: Citizen Access, Standing and Influence in Public Participation Discourses. J. Environ. Policy Plan. 2019, 21, 563-576. [CrossRef]

24. Jasanoff, S. A mirror for science. Public Underst. Sci. 2014, 23, 21-26. [CrossRef]

25. Hendriks, C.M.; Grin, J. Contextualizing reflexive governance: The politics of Dutch transitions to sustainability. J. Environ. Policy Plan. 2007, 9, 333-350. [CrossRef] 
26. Walker, G.; Cass, N. Carbon reduction, "the public" and renewable energy: Engaging with socio-technical configurations. Area 2007, 39, 458-469. [CrossRef]

27. Smith, A. Civil society in sustainable energy transitions. In Governing the Energy Transition: Reality, Illusion, or Necessity; Verbong, G., Loorbach, D., Eds.; Routledge: New York, NY, USA, 2012; pp. 180-202.

28. Irwin, A. The politics of talk: Coming to terms with the "new" scientific governance. Soc. Stud. Sci. 2006, 36, 299-320. [CrossRef]

29. Irwin, A. Constructing the scientific citizen: Science and democracy in the biosciences. Public Underst. Sci. 2001, 10, 1-18. [CrossRef]

30. Hagendijk, R.; Irwin, A. Public deliberation and governance: Engaging with science and technology in contemporary Europe. Minerva 2006, 44, 167-184. [CrossRef]

31. Chilvers, J.; Kearnes, M. Remaking Participation in Science and Democracy. Sci. Technol. Hum. Values 2019, 45, 347-380. [CrossRef]

32. Krueger, R.A.; Casey, M.A. Focus Groups: A Practical Guide for Applied Research; SAGE Publications, Inc.: London, UK, 2009.

33. Ransdorp, S.; Osseweijer, P. Maatschappelijke Roadmap voor de Biobased Economy; Stichting BE-Basic: Delft, The Netherlands, 2016.

34. Michael, M. Publics performing publics: Of PiGs, PiPs and politics. Public Underst. Sci. 2009, 18, 617-631. [CrossRef]

35. Braun, K.; Schultz, S. “. . a certain amount of engineering involved": Constructing the public in participatory governance arrangements. Public Underst. Sci. 2010, 19, 403-419. [CrossRef] [PubMed]

36. Callon, M.; Lascoumes, P.; Barthe, Y. Acting in an Uncertain World: An Essay on Technical Democracy; MIT Press: Cambridge, MA, USA, 2009.

37. Bosman, R.; Rotmans, J. Transition Governance towards a Bioeconomy: A Comparison of Finland and The Netherlands. Sustainability 2016, 8, 1017. [CrossRef]

38. Hausknost, D.; Schriefl, E.; Lauk, C.; Kalt, G. A transition to which bioeconomy? An exploration of diverging techno-political choices. Sustainability 2017, 9, 669. [CrossRef]

39. Van der Molen, F.; Ludwig, D.; Consoli, L.; Zwart, H. Global challenges, Dutch solutions? The shape of responsibility in Dutch science and technology policies. J. Responsib. Innov. 2019, 6, 340-345. [CrossRef]

40. Liobikiene, G.; Chen, X.; Streimikiene, D.; Balezentis, T. The trends in bioeconomy development in the European Union: Exploiting capacity and productivity measures based on the land footprint approach. Land Use Policy 2020, 91, 104375. [CrossRef]

41. Falcone, P.M.; González García, S.; Imbert, E.; Lijó, L.; Moreira, M.T.; Tani, A.; Tartiu, V.E.; Morone, P. Transitioning towards the bio-economy: Assessing the social dimension through a stakeholder lens. Corp. Soc. Responsib. Environ. Manag. 2019, 26, 1135-1153. [CrossRef]

42. Liobikiene, G.; Balezentis, T.; Streimikiene, D.; Chen, X. Evaluation of bioeconomy in the context of strong sustainability. Sustain. Dev. 2019, 27, 955-964. [CrossRef]

43. Fevolden, A.M.; Coenen, L.; Hansen, T.; Klitkou, A. The role of trials and demonstration projects in the development of a sustainable bioeconomy. Sustainability 2017, 9, 419. [CrossRef]

44. Farla, J.; Markard, J.; Raven, R.; Coenen, L. Sustainability transitions in the making: A closer look at actors, strategies and resources. Technol. Forecast. Soc. Chang. 2012, 79, 991-998. [CrossRef]

45. D'Adamo, I.; Gastaldi, M.; Rosa, P. Recycling of end-of-life vehicles: Assessing trends and performances in Europe. Technol. Forecast. Soc. Chang. 2020, 152, 119887. [CrossRef]

46. Lynch, D.; Kupper, F.; Broerse, J. Toward a socially desirable EU research and innovation agenda on urban waste: A transnational EU citizen consultation. Sustainability 2018, 10, 1641. [CrossRef]

(C) 2020 by the authors. Licensee MDPI, Basel, Switzerland. This article is an open access article distributed under the terms and conditions of the Creative Commons Attribution (CC BY) license (http://creativecommons.org/licenses/by/4.0/). 